\title{
Ozono maila maximoen bilakaera Beasain, Jaizkibel eta Valderejon (2004-2008)
}

\author{
Elena Agirre Basurko ${ }^{1 *}$, Luis Javier Rodriguez Barron ${ }^{2}$, Albaro Anta Sanz ${ }^{3}$ \\ ${ }^{1}$ Matematika eta Zientzia Esperimentalen Didaktika Saila. \\ Gasteizko Irakasleen Unibertsitate-Eskola. \\ Euskal Herriko Unibertsitatea (UPV/EHU) \\ ${ }^{2}$ Elikagaien Teknologia Saila. Farmazia Fakultatea. \\ Euskal Herriko Unibertsitatea (UPV/EHU) \\ ${ }^{3}$ Analista programatzailea. Vitoria-Gasteiz \\ * elena.agirre@ehu.es
}

Laburpena: Artikulu honetan, gaur egun aire-kutsatzaile kezkagarrienetakoa den troposferako ozonoa da aztergai. Euskal Autonomia Erkidegoko Aire Kalitatea Kontrolatzeko eta Zaintzeko Sareko Beasain, Jaizkibel eta Valderejo estazioetan 2004-2008 denboraldian neurtutako eguneko ozono kontzentrazio maximoen analisi estatistiko deskribatzailea egin da eta giza osasunaren babeserako atalaseak noiz gainditu ziren aztertu da.

\begin{abstract}
This paper is focused on the study of tropospheric ozone, which is currently one of the most relevant air pollutants. Research has been done consisting on a descriptive statistical analysis of the daily maximum ozone levels recorded during 2004-2008 at several stations of the Air Quality Monitoring Network of the Basque Country: Beasain, Jaizkibel and Valderejo. It also includes the study of the thresholds for ozone concentrations in air to protect human health.
\end{abstract}

\section{SARRERA}

Aire-kalitateari eta aire-kutsatzaileei buruz aritzean, maiz agertzen da ozonoa $\left(\mathrm{O}_{3}\right)$. Aire-kutsatzaileak, ingurunean kalteak sortzen dituzten konposatuak dira [1]. Lehen mailako kutsatzaileak igorpen-fokoetatik (zirkulaziotik, hegazkinetatik, industria-jardueretatik, giza jardueretatik,...) zuzenean igortzen dira atmosferara. Hauen artean badaude sufre-oxidoak, karbono monoxidoa, partikulak eta osagai organikoak. Bigarren mailako kutsatzaileak aldiz, lehenengo mailako kutsatzaileek atmosferan jasotzen 
dituzten erreakzio kimikoen ondorioz sortzen dira. Talde honetako kutsatzailea da ozonoa, nitrogeno-oxidoek eta konposatu organikoek eguzkierradiaziopean erreakzionatzean sortzen baita.

Esan beharrekoa da bi ozono mota daudela, atmosferako kokapenaren arabera: i) estratosferako ozonoa, atmosferako 20-60 km bitartean dagoena eta eguzki-izpien erradiazioetatik babesten gaituena («ozono ona»), eta ii) troposferako ozonoa, atmosferako $0-20 \mathrm{~km}$ bitartean dagoena eta gizakiontzat eta ingurugirorako kaltegarria izan daitekeena («ozono txarra») [2]. Askotan, terminologia laburtze aldera, troposferako ozono den aire-kutsatzaileari buruz aritzean ozono hitz bakarra erabiltzen da. Artikulu honetan ere horrela egingo da.

1977 urtetik kudeatzen du Eusko Jaurlaritzak Euskal Autonomia Erkidegoko (EAE) Aire Kalitatea Kontrolatzeko eta Zaintzeko Sarea. Garai hartan sufre dioxidoa $\left(\mathrm{SO}_{2}\right)$ eta partikula esekiak ziren airearen kutsatzaile nagusiak zenbait herrialdetan [3]. Egun, aire-kutsatzaile nagusien artean badaude nitrogeno dioxidoa $\left(\mathrm{NO}_{2}\right)$, partikula esekiak $\left(\mathrm{PM}_{10}\right)$, sufre dioxidoa $\left(\mathrm{SO}_{2}\right)$, karbono monoxidoa $(\mathrm{CO})$ eta ozonoa $\left(\mathrm{O}_{3}\right)$ [4]. Gainera, azken urteetan Europako Batasunak arreta berezia jarri du aire-kalitateak osasunean duen eraginean, eta gizakiongan eragin ditzakeen kalteengatik ozonoa da osasunarekin lotutako kutsatzaile kezkagarrienetako bat [5]. Europako Batasuneko 2008/50/CE zuzentarauak [6] giza osasuna babesteko ozonoaren informazio-atalasea eta alerta-atalasea ezarri ditu. Batetik, orduko batezbesteko ozono kontzentrazioak $180 \mu \mathrm{g} / \mathrm{m}^{3}$ baino handiagoak direnean, biztanleria jakitun jartzeko, esaten da atalasea (informazio-atalasea) gainditu dela. Bestetik, hiru orduan zehar ozono kontzentrazioak $240 \mu \mathrm{g} / \mathrm{m}^{3}-\mathrm{ko}$ muga gainditzen duenean alerta-atalasea gainditu dela onartzen da.

Halaber, EAEko aire-kalitatearen ebaluazioa egiteko aire-kalitatearen indizea erabiltzen da [7]. Hurrengo taulan adierazi dira kutsatzaileen balioen araberako indizeak eta indizeei esleitutako koloreak.

1. taula. Aire-kutsatzaileen indizeak $\left(\mu \mathrm{g} / \mathrm{m}^{3}\right)$ Euskal Autonomia Erkidegoan.

\begin{tabular}{|l|l|r|c|c|c|r|}
\hline Kolorea & \multicolumn{1}{|c|}{ Indizea } & \multicolumn{1}{c|}{$\mathrm{NO}_{2}$} & \multicolumn{1}{c|}{$\mathrm{PM}_{10}$} & \multicolumn{1}{c|}{$\mathrm{SO}_{2}$} & \multicolumn{1}{c|}{$\mathrm{CO}$} & \multicolumn{1}{c|}{$\mathrm{O}_{3}$} \\
\hline & Ona & $0-105$ & $0-25$ & $0-62,5$ & $0-5.000$ & $0-90$ \\
\hline & Onargarria & $105,1-210$ & $25,1-50$ & $62,6-125$ & $5.000,1-10.000$ & $90,1-160$ \\
\hline & Ertaina & $210,1-252$ & $50,1-65$ & $125,1-146$ & $10.000,1-14.000$ & $160,1-180$ \\
\hline & Txarra & $252,1-330$ & $65,1-82,5$ & $146,1-187,5$ & $14.000,1-18.000$ & $180,1-270$ \\
\hline & Oso txarra & $330,1-699$ & $82,6-138$ & $187,6-250$ & $18.000,1-24.000$ & $270,1-360$ \\
\hline & Arriskutsua & $>699$ & $>138$ & $>250$ & $>24.000$ & $>360$ \\
\hline
\end{tabular}


Aire-kalitatearen indizearen arabera, www.ingurumena.ejgv.euskadi.net web-orrian azaltzen da EAEko aire-kalitatea era grafikoan, 1. irudiko adibidean adierazten den moduan:

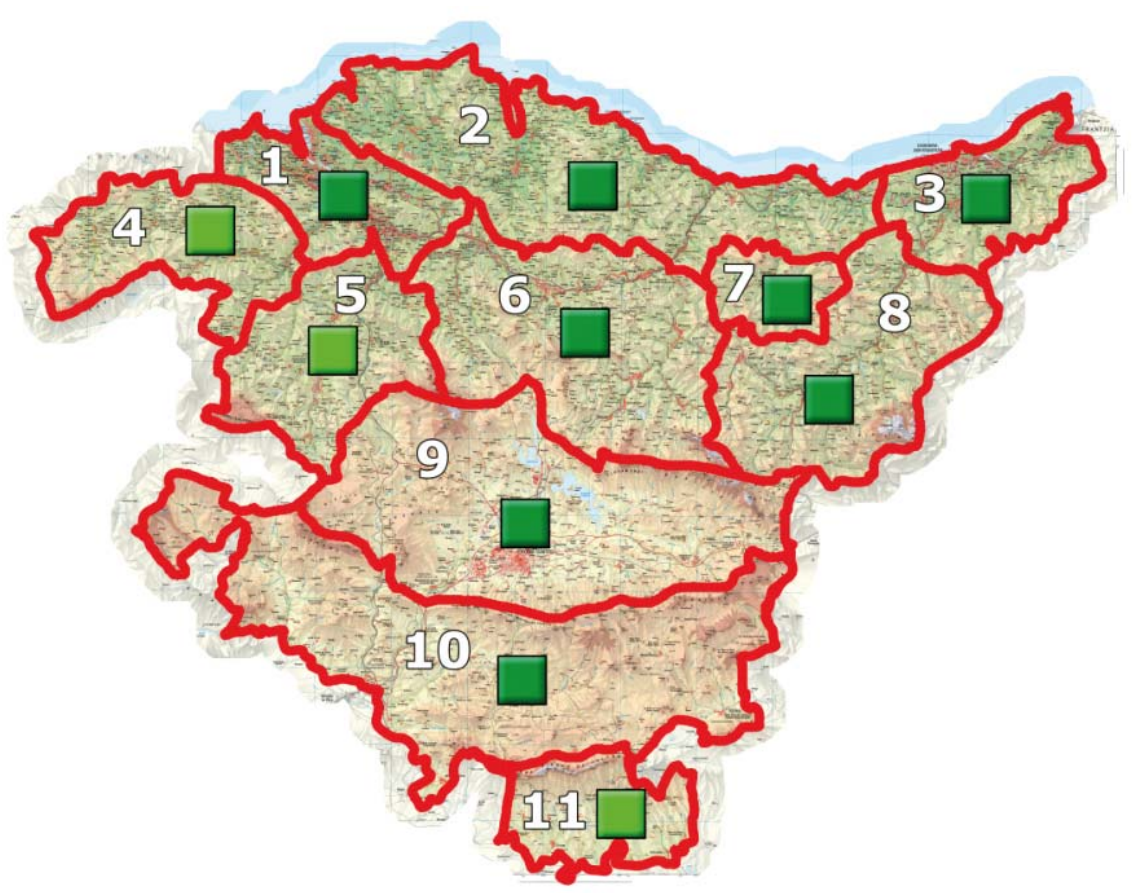

1. irudia. Euskadiko aire-kalitatearen informazioa (2013/02/27).

Ozonoak ez ditu kalte berdinak sortzen gizaki guztietan. Hauek dira ozonoarekiko sentiberak direnak: aire zabalean diharduten umeak, aire zabalean etengabe lan edo jarduera fisikoa egiten dauden helduak eta arnasketa arazoak dituzten lagunak. Arnasketaren erritmoa azkartzen denean handitu egiten da birikietan sartzen den ozono kantitatea, eta ondorioz, aire zabalean ariketa fisikoa egitean ozonoak eragin ditzakeen kalteak sor edo handitu daitezke. Horregatik, osasuna babesteko hurrengo neurriak (2. taula) proposatzen ditu Osakidetzak [8]: 
2. taula. Ozonoaren osasunaren gaineko eraginak eta osasuna babesteko neurriak.

\begin{tabular}{|c|c|c|}
\hline $\begin{array}{c}\text { Aire-kalitatea } \\
\text { ozonoagatik }\end{array}$ & Eraginak osasunean & Osasuna babesteko neurriak \\
\hline Ona & Osasunerako arazorik ez. & \\
\hline $\begin{array}{l}\text { Onargarria } \\
\text { ala ertaina }\end{array}$ & $\begin{array}{l}\text { Gizaki batzuk arnasketa ara- } \\
\text { zoak nabari ditzakete, jarduera } \\
\text { fisikoa aire zabalean egitean. }\end{array}$ & $\begin{array}{l}\text { Lagun hauei aire zabalean jarduera } \\
\text { fisiko gutxiago egitea komeniko li- } \\
\text { tzaieke, eguerdiko orduetan bereziki. }\end{array}$ \\
\hline Txarra & $\begin{array}{l}\text { Ozonoarekiko sentiberak di- } \\
\text { ren gizakiek arnasketa-sinto- } \\
\text { mak (eztula, mina arnasa sa- } \\
\text { kon hartzean) eta arnasteko } \\
\text { zailtasunak izan ditzakete. } \\
\text { Gainontzeko biztanleek ar- } \\
\text { nasketa arazoren bat nabari } \\
\text { dezakete jarduera fisiko bizia } \\
\text { eta denbora luzez egitean. }\end{array}$ & $\begin{array}{l}\text { Ozonoarekiko sentiberak diren gi- } \\
\text { zakiek, gutxiagotan egin behar dute } \\
\text { jarduera fisiko bizia eta denbora lu- } \\
\text { zez aire zabalean, batez ere eguerdi- } \\
\text { ko orduetan. } \\
\text { Gainontzeko gizakiak, batez ere ar- } \\
\text { nasketa arazoak azaltzen badira, } \\
\text { aire zabalean jarduera fisiko bizia } \\
\text { eta denbora luzez egitea mugatzen } \\
\text { saiatu behar dira, eguerdiko ordue- } \\
\text { tan bereziki. }\end{array}$ \\
\hline $\begin{array}{l}\text { Oso } \\
\text { txarra ala } \\
\text { arriskutsua }\end{array}$ & $\begin{array}{l}\text { Litekeena da ozonoarekiko } \\
\text { sentiberak diren lagunek ar- } \\
\text { nasketa-sintoma larriak pai- } \\
\text { ratzea eta arnasteko zailtasun } \\
\text { handiak izatea. } \\
\text { Gainontzeko biztanleek, lite- } \\
\text { keena da, arnasketa arazoak } \\
\text { nabaritzea ariketa fisiko bizia } \\
\text { eta denbora luzez egitean. }\end{array}$ & $\begin{array}{l}\text { Ozonoarekiko sentiberak diren la- } \\
\text { gunek aire zabalean egin beharreko } \\
\text { ahalegin fisiko oro ekidingo dituzte. } \\
\text { Gainontzeko biztanleek, bereziki ar- } \\
\text { nasketa arazoak jaso ditzaketenek, } \\
\text { mugatu egingo dute aire zabalean } \\
\text { jarduera fisiko biziak eta denbora } \\
\text { luzez egitea, batez ere eguerdiko or- } \\
\text { duetan. }\end{array}$ \\
\hline
\end{tabular}

Hau guztia kontuan hartuta, esan daiteke komenigarria dela ozono mailen neurketa, jarraipena eta kontrola egitea.

\section{DATA-BASEA}

EAEko Aire-Kalitatea Kontrolatzeko eta Zaintzeko Sarean zenbait aire-kutsatzaileren eta meteorologia aldagairen orduko batezbesteko neurketak jasotzen dira. Urteetan zehar EAEko Aire Kalitatea Kontrolatzeko eta Zaintzeko Sarea zabaldu da, eta egun hamaika eremutan (1 irudia) banatuta dago: (1) Nerbioi Behea, (2) Kostaldea, (3) Donostialdea, (4) Enkarterriak, (5) Nerbioi Garaia, (6) Ibaizabal-Debagoiena, (7) Urola Garaia, (8) Oria Garaia, (9) Arabako Lautada, (10) Hegoaldeko Araba eta (11) Arabako Errioxa. Artikulu honetan hiru eremutako estazioak hartu dira: Beasain 
(8 eremuan, Oria Garaian), Jaizkibel (2 eremuan, Kostaldean) eta Valderejo (10 eremuan, Hegoaldeko Araban). Eremu bakoitzean hainbat estazio daude eta estazioen ezaugarriak ez dira berdinak. Esate baterako, Jaizkibel estazioa kostan dago, eta Beasain eta Valderejo, barnealdean. Gainera, Beasain hiriko estazioa da, eta aldiz, Jaizkibel eta Valderejo landa-estazioak dira. Beraz, estazio ezberdinek ozonoagatiko aire-kalitate ezberdina izan dezakete. Hurrengo atalean hiru estazio hauetan 2004 urtetik 2008 urtera egunero jaso ziren ozono maila maximoak aztertu dira.

\section{EGUNEKO OZONO MAILA MAXIMOEN ANALISIA}

EAEko Aire Kalitatea Kontrolatzeko eta Zaintzeko Sarean jasotako datuen analisi estatistikotik abiatuz, aire-kalitatearen egoera deskriba daiteke. Artikulu honetan Beasain, Jaizkibel eta Valderejo estazioetan 2004-2008 denboraldian neurtutako eguneko ozono kontzentrazio maximoen analisi estatistiko deskribatzailea aurkeztu da eta balio maximo horiek ozonoaren informazio-atalasea $\left(180 \mu \mathrm{g} / \mathrm{m}^{3}\right)$ eta alarma-atalasea $\left(240 \mu \mathrm{g} / \mathrm{m}^{3}\right)$ zenbat aldiz eta noiz gainditu zituzten zehaztu da.

\subsection{Eguneko ozono maila maximoa Beasain estazioan 2004-2008 denboraldian}

Hasteko, 3. taulan aurkeztu diren estatistiko deskribatzaileek $\left(\mu \mathrm{g} / \mathrm{m}^{3}\right.$-an neurtuta) eguneko ozono kontzentrazio maximoa neurtzen duen maxO3 aldagaiaren portaera laburbiltzen dute, Beasain estazioan 2004-2008 denboraldian.

3. taula. Ozono kontzentrazio maximoak $\left(\mu \mathrm{g} / \mathrm{m}^{3}\right)$ Beasainen (2004-2008).

\begin{tabular}{|l|r|r|r|r|r|}
\hline \multicolumn{7}{|c|}{ maxO3 } & 2004 & 2005 & 2006 & 2007 & 2008 \\
\hline Minimoa & 2,00 & 1,00 & 3,00 & 3,00 & 4,00 \\
\hline Maximoa & 132,00 & 158,00 & 184,00 & 173,00 & 194,00 \\
\hline Batezbestekoa & 52,81 & 58,74 & 61,59 & 60,61 & 65,72 \\
\hline Mediana & 52,50 & 59,00 & 58,50 & 60,00 & 64,00 \\
\hline Moda & 51,00 & 67,00 & 55,00 & 68,00 & 56,00 \\
\hline Desb. Tipikoa & 24,32 & 24,61 & 28,36 & 25,90 & 30,03 \\
\hline$P_{95}$ & 91,30 & 99,00 & 102,00 & 101,25 & 111,00 \\
\hline$P_{99}$ & 120,33 & 121,70 & 172,60 & 151,40 & 192,50 \\
\hline
\end{tabular}


Taula honetako balioek erakusten duten moduan, Beasain estazioan eguneko ozono maila maximoaren balio minimoak 1 eta $4 \mu \mathrm{g} / \mathrm{m}^{3}$ bitartekoak izan ziren eta maximoak 132 - $194 \mu \mathrm{g} / \mathrm{m}^{3}$ tartekoak 2004-2008 denboraldian. Aztergai den $\operatorname{maxO3}$ aldagaiaren batezbestekoa $52,81 \mu \mathrm{g} / \mathrm{m}^{3}-65,72 \mu \mathrm{g} / \mathrm{m}^{3}$ tartekoa izan zen, desbideratze tipikoaren balioak $24,32-30,03 \mu \mathrm{g} / \mathrm{m}^{3}$ bitartekoak izan zirelarik. Medianaren balioak $52,50 \mu \mathrm{g} / \mathrm{m}^{3}$ eta $64 \mu \mathrm{g} / \mathrm{m}^{3}$ bitartekoak izan ziren. Kasu honetan, mediana eta batezbestekoaren artean ez dago diferentzia adierazgarririk, eta beraz medianak joera zentrala adierazten du. Maiztasun handienez jaso zen eguneko ozono maila maximoa (moda) gutxienez $51 \mu \mathrm{g} / \mathrm{m}^{3}$ eta gehienez $68 \mu \mathrm{g} / \mathrm{m}^{3}$-koa izan zen. 95. Eta 99. ordenatako pertzentilak kalkulatu dira: 95 . ordenako pertzentilen balioak 91 - 111 bitartekoak dira eta 99. ordenako pertzentilek $120,33-192,50 \mu \mathrm{g} / \mathrm{m}^{3}$ tarteko balioak hartzen dituzte. Beraz, kasuen $\%$ 5ean eguneko ozono kontzentrazio maximoak gehienez $111 \mu \mathrm{g} / \mathrm{m}^{3}$-koak izan ziren, eta kasuen \% 1ean besterik ez ziren izan $192,50 \mu \mathrm{g} / \mathrm{m}^{3}$ baino altuagoak. maxO3 aldagaiaren batezbesteko, mediana, maximo eta pertzentilen balioek urtez urteko joera gorakorra erakusten dute 2004-2008 denboraldian.

Estazio honetan 2004-2008 denboraldian ez zen gainditu ozonoaren alerta-atalasea $\left(240 \mu \mathrm{g} / \mathrm{m}^{3}\right)$ eta informazio-atalasea $\left(180 \mu \mathrm{g} / \mathrm{m}^{3}\right)$ soilik bi urtetan gainditu zen: 2006 urteko maximoa $184 \mu \mathrm{g} / \mathrm{m}^{3}$ da, eta 2008 urtekoa $194 \mu \mathrm{g} / \mathrm{m}^{3} .4$ taulan zehatzago ikus daitekeen moduan, Beasain estazioan aztergai den denboraldian eguneko ozono kontzentrazio maximoak 2004-2008 denboraldiko soilik 7 egunean izan ziren $180 \mu \mathrm{g} / \mathrm{m}^{3}$ baino

4. taula. maxO3 aldagaiaren giza osasunaren babeserako atalaseak (Beasain, 2004-2008).

\begin{tabular}{|c|c|c|}
\hline Estazioa & Data & $\operatorname{maxO} 3\left(\mu \mathrm{g} / \mathrm{m}^{3}\right)$ \\
\hline \multirow{5}{*}{ Beasain } & $2006 / 06 / 2114: 00$ & 181 \\
\cline { 2 - 3 } & $2006 / 07 / 1817: 00$ & 183 \\
\cline { 2 - 3 } & $2006 / 09 / 0815: 00$ & 184 \\
\cline { 2 - 3 } & $2008 / 06 / 2411: 00$ & 194 \\
\cline { 2 - 3 } & $2008 / 07 / 0916: 00$ & 194 \\
\cline { 2 - 3 } & $2008 / 07 / 2317: 00$ & 191 \\
\cline { 2 - 3 } & $2008 / 08 / 2916: 00$ & 194 \\
\hline
\end{tabular}


handiagoak. Gainditze hauek udan jaso ziren (ekaina, uztaila, abuztua eta irailean),11:00 eta 17:00ak bitartean, eguzkiaren erradiazioak indartsuagoak diren garaian hain zuzen ere. Bukatzeko, adierazi behar da $240 \mu \mathrm{g} / \mathrm{m}^{3}$-ak ez zirela gainditu inoiz.

2. irudiko lerro diagraman ikus daiteke eguneko ozono kontzentrazio maximoek Beasain estazioan 2004-2008 denboraldian izandako bilakaera.

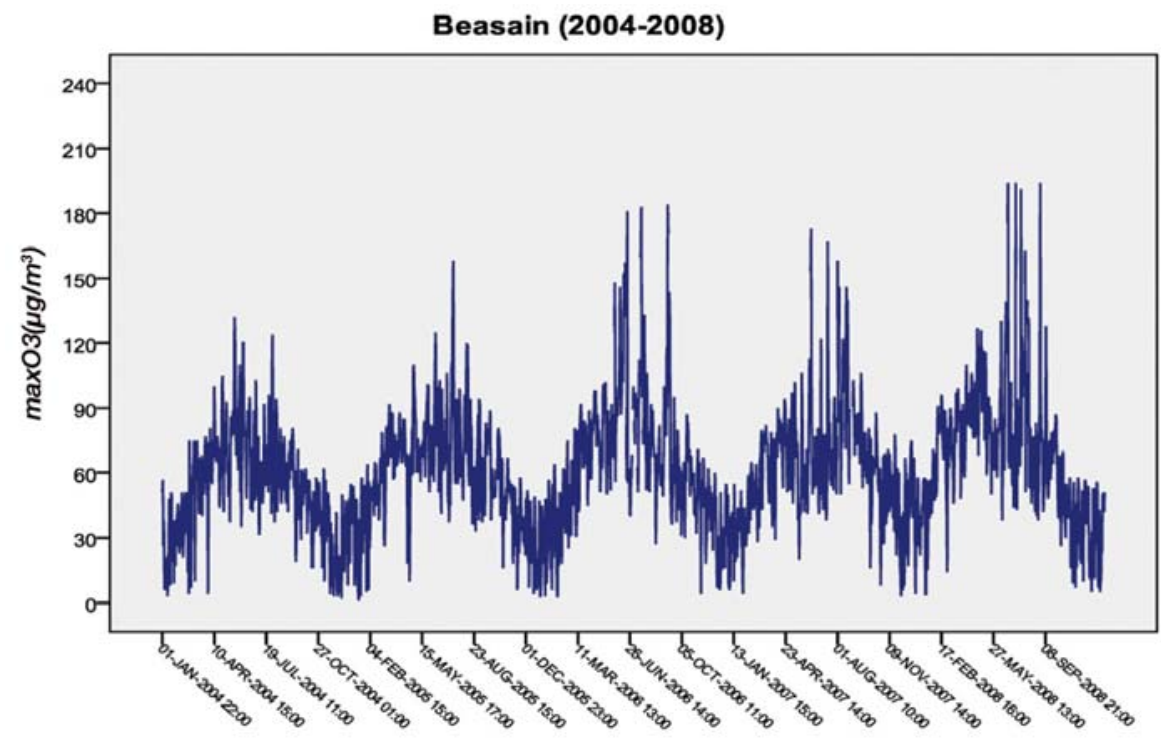

2. irudia. Eguneko ozono kontzentrazio maximoak (Beasain, 2004-2008).

2 irudian $\max O 3$ aldagaiaren urtez urteko izaera ziklikoa nabari daiteke 2004tik 2008ra bitartean. Eguneko ozono kontzentrazio maximoek joera gorakorra dutela onar daiteke, oro har, 2004-2006 denboraldian gora egin zuten maxO3 aldagaiaren balioek, 2007 urtean zerbait jaitsi egin ziren eta berriro ere igo ziren 2008 urtean, 2006 urteko kontzentrazioak gainditu zirelarik. Halaber, 2. irudian ikus daiteke 2006 eta 2008 urteetan Beasain estazioan balio maximo altuagoak izan zirela.

3. irudiko kutxa-diagramak adierazten duenez, Beasain estazioan 2004-2008 denboraldian eguneko ozono kontzentrazio maximoak altuagoak izan ziren apirila eta iraila bitartean. Esan beharrekoa da muturreko balioak ere hilabete horietan jaso zirela. 


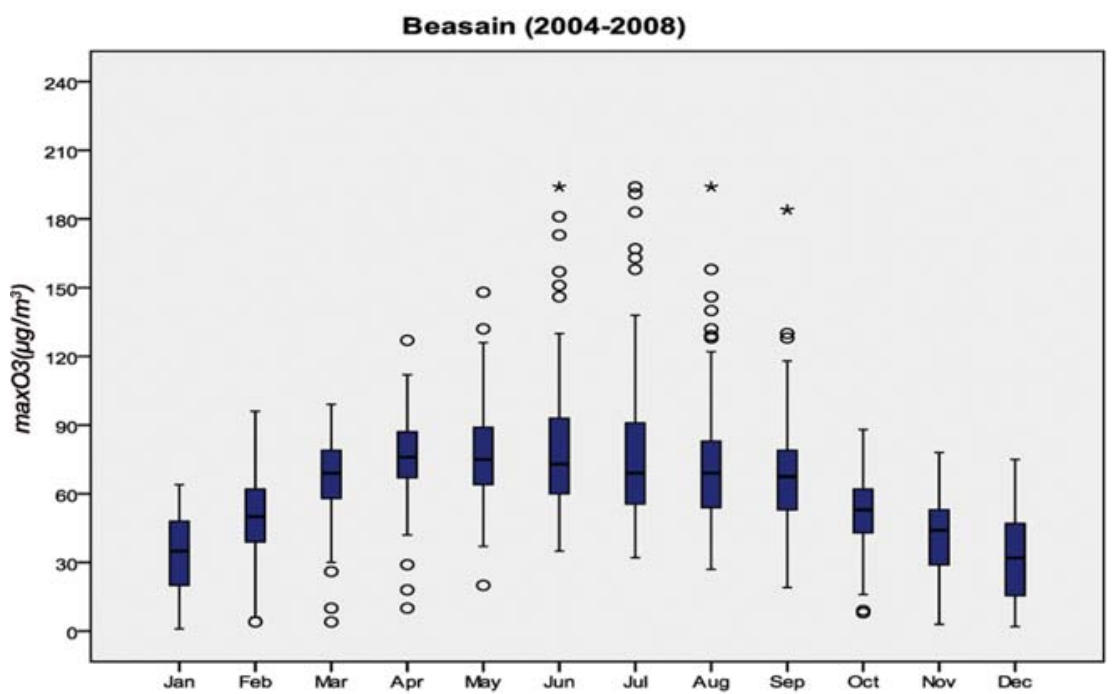

3. irudia. Eguneko ozono kontzentrazio maximoen kutxa-diagrama (Beasain, 2004-2008).

\subsection{Eguneko ozono maila maximoa Jaizkibel estazioan 2004-2008 denboraldian}

2004 urteko uztailaren 21etik aurrera daude EAEko Aire Kalitatea Kontrolatzeko eta Zaintzeko Sarean Jaizkibel estazioko ozono kontzentrazioak. Honako 5. taulan ikus daitezke eguneko ozono kontzentrazio maximoak neurtzen dituen aldagaiaren (maxO3) estatistiko deskribatzaileak azaltzen ditu:

5. taula. Ozono kontzentrazio maximoak $\left(\mu \mathrm{g} / \mathrm{m}^{3}\right)$ Jaizkibelen (2004-2008).

\begin{tabular}{|l|r|r|r|r|r|}
\hline \multicolumn{7}{|c|}{ Jaizkibel } \\
\hline \multicolumn{1}{|c|}{ maxO3 } & 2004 & 2005 & 2006 & 2007 & 2008 \\
\hline Minimoa & 36,00 & 41,00 & 43,00 & 38,00 & 43,00 \\
\hline Maximoa & 171,00 & 207,00 & 193,00 & 168,00 & 150,00 \\
\hline Batezbestekoa & 83,21 & 91,54 & 87,62 & 88,83 & 85,94 \\
\hline Mediana & 81,00 & 87,00 & 84,00 & 85,50 & 85,00 \\
\hline Moda & 71,00 & 74,00 & 75,00 & 76,00 & 80,00 \\
\hline Desb. tipikoa & 18,95 & 24,54 & 22,73 & 21,92 & 18,44 \\
\hline $\mathrm{P}_{95}$ & 120,40 & 140,00 & 137,00 & 129,75 & 118,75 \\
\hline $\mathrm{P}_{99}$ & 158,20 & 169,34 & 173,48 & 152,45 & 140,70 \\
\hline
\end{tabular}


Batetik, 2004-2008 denboraldian Jaizkibel estazioan maxO3 aldagaiaren balio minimoak 36 eta $43 \mu \mathrm{g} / \mathrm{m}^{3}$ tartekoak izan ziren eta maximoak $150-207 \mu \mathrm{g} / \mathrm{m}^{3}$ tartekoak. Eguneko ozono kontzentrazio maximoaren batezbestekoa $83,21-91,54 \mu \mathrm{g} / \mathrm{m}^{3}$ bitartekoa izan zen eta desbideratze tipikoa $18,44-24,54 \mu \mathrm{g} / \mathrm{m}^{3}$ bitartekoa. Medianaren balioak, hau da, $81 \mu \mathrm{g} / \mathrm{m}^{3}$ eta $87 \mu \mathrm{g} / \mathrm{m}^{3}$ bitartekoak, ez dira oso urrun ikusi batezbestekoaren balioetatik. Maiztasun handienez jaso zen eguneko ozono maila maximoa gutxienez $71 \mu \mathrm{g} / \mathrm{m}^{3}$-koa izan zen eta gehienez $80 \mu \mathrm{g} / \mathrm{m}^{3}$-koa. 95 . ordenako pertzentilen balioak $118,75-140 \mu \mathrm{g} / \mathrm{m}^{3}$ bitartekoak dira eta 99 . ordenako pertzentilak $140,70-173,48 \mu \mathrm{g} / \mathrm{m}^{3}$ tarteko balioak hartzen dituzte. Honek esan nahi du kasuetako \% 1ean baino gutxiagotan gainditu zela informazio-atalasea $\left(180 \mu \mathrm{g} / \mathrm{m}^{3}\right)$, inoiz gainditu bazen. Hain zuzen ere, 6 taulan jaso dira gainditze hauek.

6. taula. maxO3 aldagaiaren giza osasunaren babeserako atalaseak (Jaizkibel, 2004-2008).

\begin{tabular}{|c|c|c|}
\hline Estazioa & Data & $\operatorname{maxO3}\left(\mu \mathrm{g} / \mathrm{m}^{3}\right)$ \\
\hline \multirow{5}{*}{ Jaizkibel } & $2005 / 05 / 2718: 00$ & 207 \\
\cline { 2 - 3 } & $2005 / 07 / 1418: 00$ & 183 \\
\cline { 2 - 3 } & $2006 / 07 / 0116: 00$ & 185 \\
\cline { 2 - 3 } & $2006 / 07 / 1715: 00$ & 193 \\
\cline { 2 - 3 } & $2006 / 07 / 1819: 00$ & 186 \\
\hline
\end{tabular}

6. taulak erakusten du, aztergai den aldagaiaren balio maximoek Jaizkibelen 2004-2008 denboraldian $180 \mu \mathrm{g} / \mathrm{m}^{3}$-ak 2005 eta 2006 urteetan besterik ez dituztela gainditu: 2005 urteko bi egunetan (maiatzaren 5ean eta uztailaren 14an) eta 2006 urteko hiru egunetan (uztailaren 1, 17 eta 18an), 15:00 eta 19:00ak bitartean. Eguneko ozono kontzentrazio maximoek ez zuten gainditu ozonoaren alerta-atalasea $\left(240 \mu \mathrm{g} / \mathrm{m}^{3}\right)$.

Bestetik, 4. irudian ikus daitezke eguneko ozono kontzentrazio maximoek Jaizkibel estazioan 2004-2008 denboraldian izandako bilakaera, aldagaiaren urtez urteko portaera ziklikoa nabaria delarik. Gainera, esan daiteke kasu honetan 2007 eta 2008 urteetan maxO3 aldagaiaren balioak oro har baxuagoak direla.

Estazio honetan ere eguneko ozono maila garaienak apirila eta iraila bitartean izan ziren 2004-2008 denboraldian (5. irudia). 


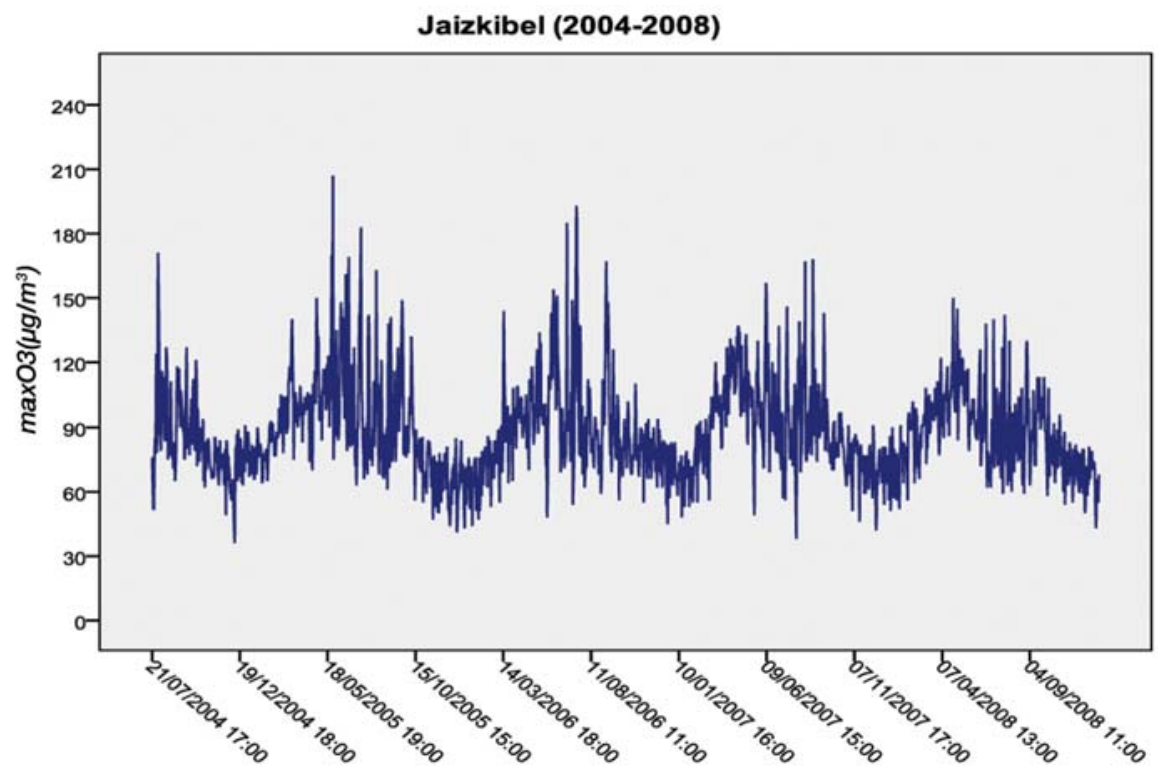

4. irudia. Eguneko ozono kontzentrazio maximoak (Jaizkibel, 2004-2008).

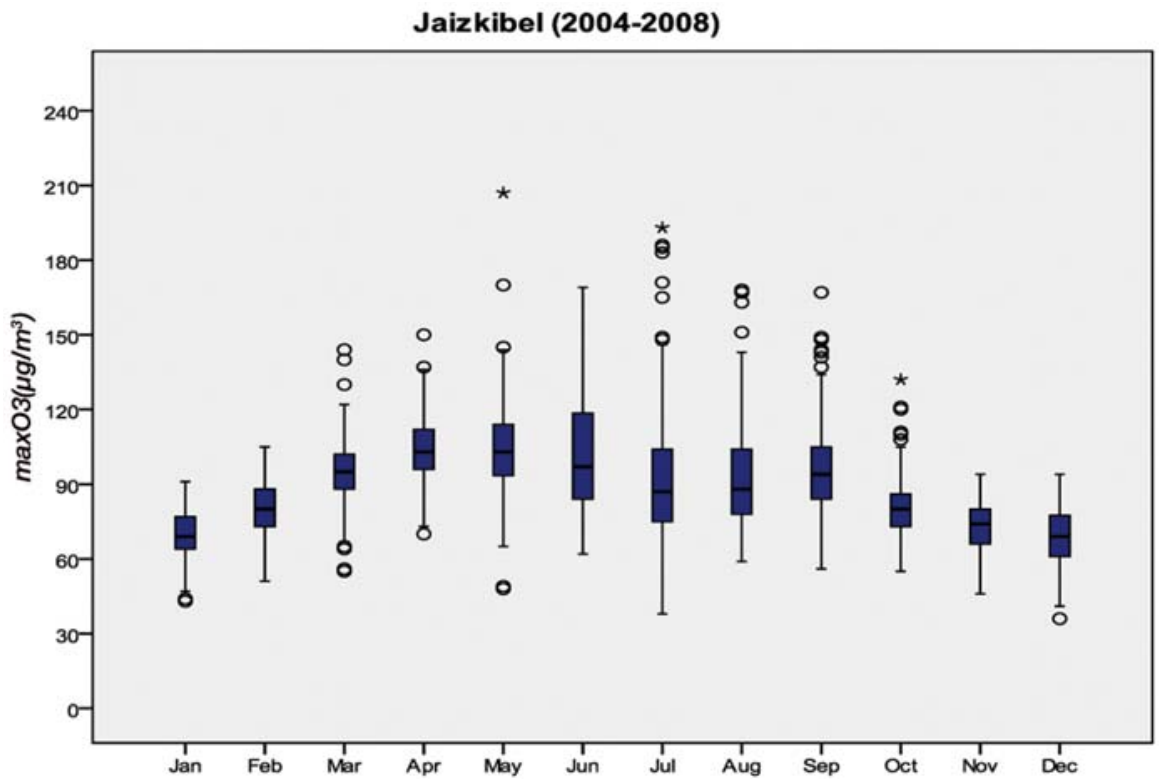

5. irudia. Eguneko ozono kontzentrazio maximoen kutxa-diagrama (Jaizkibel, 2004-2008). 
Gainera, kutxa-diagrama honetan jasota daude 2005eko maiatzeko eta 2006 urteko uztaileko ozonoaren informazio-atalasearen gainditzeak.

\subsection{Eguneko ozono maila maximoa Valderejo estazioan 2004-2008 denboraldian}

Hasteko, 7. taulan laburbildu da estatistikoek eguneko ozono kontzentrazio maximoaren analisi estatistiko deskribatzailea, Valderejo estazioan 2004-2008 denboraldian.

7. taula. Ozono kontzentrazio maximoak $\left(\mu \mathrm{g} / \mathrm{m}^{3}\right)$ Valderejoen (2004-2008).

\begin{tabular}{|l|r|r|r|r|r|}
\hline \multicolumn{7}{|c|}{ maxO3 } & 2004 & 2005 & 2006 & 2007 & 2008 \\
\hline Minimoa & 13,00 & 45,00 & 43,00 & 32,00 & 41,00 \\
\hline Maximoa & 170,00 & 166,00 & 217,00 & 175,00 & 165,00 \\
\hline Batezbestekoa & 93,37 & 86,77 & 95,08 & 91,16 & 90,38 \\
\hline Mediana & 92,50 & 83,00 & 90,00 & 88,00 & 88,00 \\
\hline Moda & 75,00 & 78,00 & 84,00 & 84,00 & 81,00 \\
\hline Desb. tipikoa & 25,24 & 19,73 & 26,27 & 23,47 & 21,18 \\
\hline P $_{95}$ & 141,00 & 126,00 & 150,50 & 132,70 & 131,30 \\
\hline P $_{99}$ & 161,30 & 151,00 & 185,06 & 154,70 & 145,66 \\
\hline
\end{tabular}

Taula honetako balioek erakusten dute, Valderejo estazioan maxO3 aldagaiaren balio minimoak 13 eta $45 \mu \mathrm{g} / \mathrm{m}^{3}$ bitartekoak izan zirela eta maximoak 165 - $217 \mu \mathrm{g} / \mathrm{m}^{3}$ bitartekoak 2004-2008 denboraldian. Eguneko ozono maila maximoaren batezbestekoa $86,77-95,08 \mu \mathrm{g} / \mathrm{m}^{3}$ bitartekoa izan zen eta desbideratze tipikoa $19,73-26,27 \mu \mathrm{g} / \mathrm{m}^{3}$ bitartekoa. Esan daiteke medianaren balioak (gutxienez $83 \mu \mathrm{g} / \mathrm{m}^{3}$ eta gehienez $92,50 \mu \mathrm{g} / \mathrm{m}^{3}$-koak) eta batezbestekoaren balioak berdintsuak direla. Maiztasun handienez jaso zen eguneko ozono maila maximoa $75-84 \mu \mathrm{g} / \mathrm{m}^{3}$ bitartekoa izan zen. 95. eta 99. ordenetako pertzentilak ere kalkulatu ziren: 95 . ordenako pertzentilen balioak $126-141 \mu \mathrm{g} / \mathrm{m}^{3}$ tartean daude eta 99 . ordenako pertzentilak 145,66 - 185,06 $\mu \mathrm{g} / \mathrm{m}^{3}$ tartean. Kasuen \% 99an aldagaiaren balioak gehienez $185,06 \mu \mathrm{g} / \mathrm{m}^{3}$-koak izan ziren. Bukatzeko, nabari da ozonoaren informazio-atalasearen gainditzeak izan zirela Valderejon 2006 urtean. 
8. taulan ikus daitekeen moduan, soilik 4 egunetan izan ziren Valderejo estazioan aztergai den denboraldian eguneko ozono kontzentrazio maximoak $180 \mu \mathrm{g} / \mathrm{m}^{3}$ baino handiagoak.

8. taula. maxO3 aldagaiaren giza osasunaren babeserako atalaseak (Valderejo, 2004-2008).

\begin{tabular}{|c|c|c|}
\hline Estazioa & Data & $\operatorname{maxO3}\left(\mu \mathrm{g} / \mathrm{m}^{3}\right)$ \\
\hline \multirow{3}{*}{ Valderejo } & $2006 / 06 / 0717: 00$ & 191 \\
\cline { 2 - 3 } & $2006 / 07 / 1017: 00$ & 217 \\
\cline { 2 - 3 } & $2006 / 07 / 1616: 00$ & 182 \\
\cline { 2 - 3 } & $2006 / 09 / 0516: 00$ & 199 \\
\hline
\end{tabular}

Gainditze hauek 2006 urteko ekaina, uztaila eta irailean (udan) jaso ziren, 16:00 eta 17:00ak bitartean, urteko garairik beroenean. Bukatzeko, Valderejo estazioan ez zen gainditu ozonoaren alerta-atalasea $\left(240 \mu \mathrm{g} / \mathrm{m}^{3}\right)$ 2004-2008 denboraldian.

Bestalde, 6. irudiko lerro grafikoan adierazi da eguneko ozono kontzentrazio maximoek Valderejo estazioan 2004-2008 denboraldian izandako bilakaera.

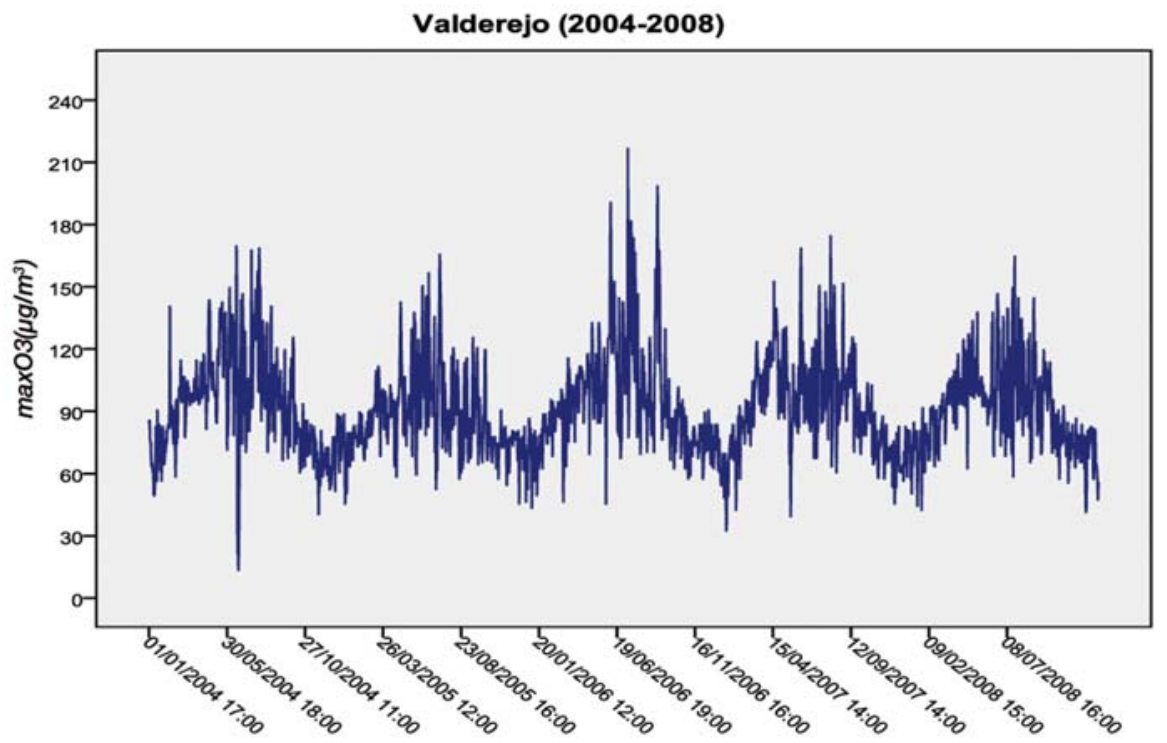

6. irudia. Eguneko ozono kontzentrazio maximoak (Valderejo, 2004-2008). 
6. irudian ikus daiteke maxO3 aldagaiaren urtez urteko izaera ziklikoaz gain, Valderejon eguneko ozono kontzentrazio maximo garaienak 2006 urtean jaso zirela. 7. irudiko kutxa-diagraman islatu dira balio horiek: balio garaienak apirila eta iraila bitartean hartu ziren eta muturreko balio altuenak ekaina eta uztailean jaso ziren.

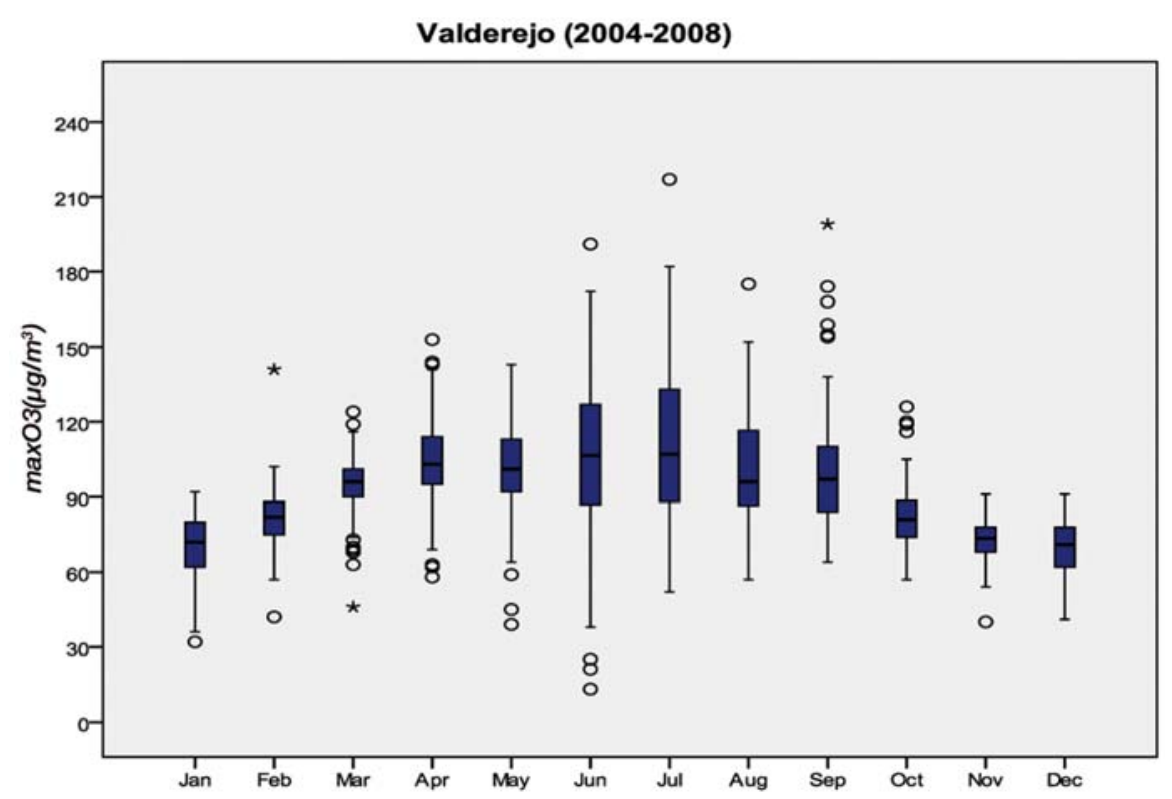

7. irudia. Eguneko ozono kontzentrazio maximoen kutxa-diagrama (Valderejo, 2004-2008).

\subsection{Eguneko ozono maila maximoak hiru estazioetan}

Frogatuta dago landa-estazioetan hiri-estazioetan baino ozono kontzentrazio handiagoak izaten direla $[9,10,11]$. Ikerketa honetan ere: maximo, mediana, kuartil eta pertzentilen balioak, oro har, Beasain estaziorako lortutakoak baino handiagoak dira Jaizkibel eta Valderejon (8. irudia).

Halaber, 9. irudian ikus daitekeenez, maxO3 aldagaiaren batez besteko balioak ere Beasainen (urdinez) baino handiagoak dira Jaizkibel (arrosaz) eta Valderejon (horiz).

Batetik, ozonoa bigarren mailako kutsatzailea da; ez da isurtzen zuzenean atmosferara. Ozonoaren igorpen-foko garrantzitsuenak zirkulazioa eta industriako errekuntza prozesuak izan arren, erreakzio fotokimikoen 


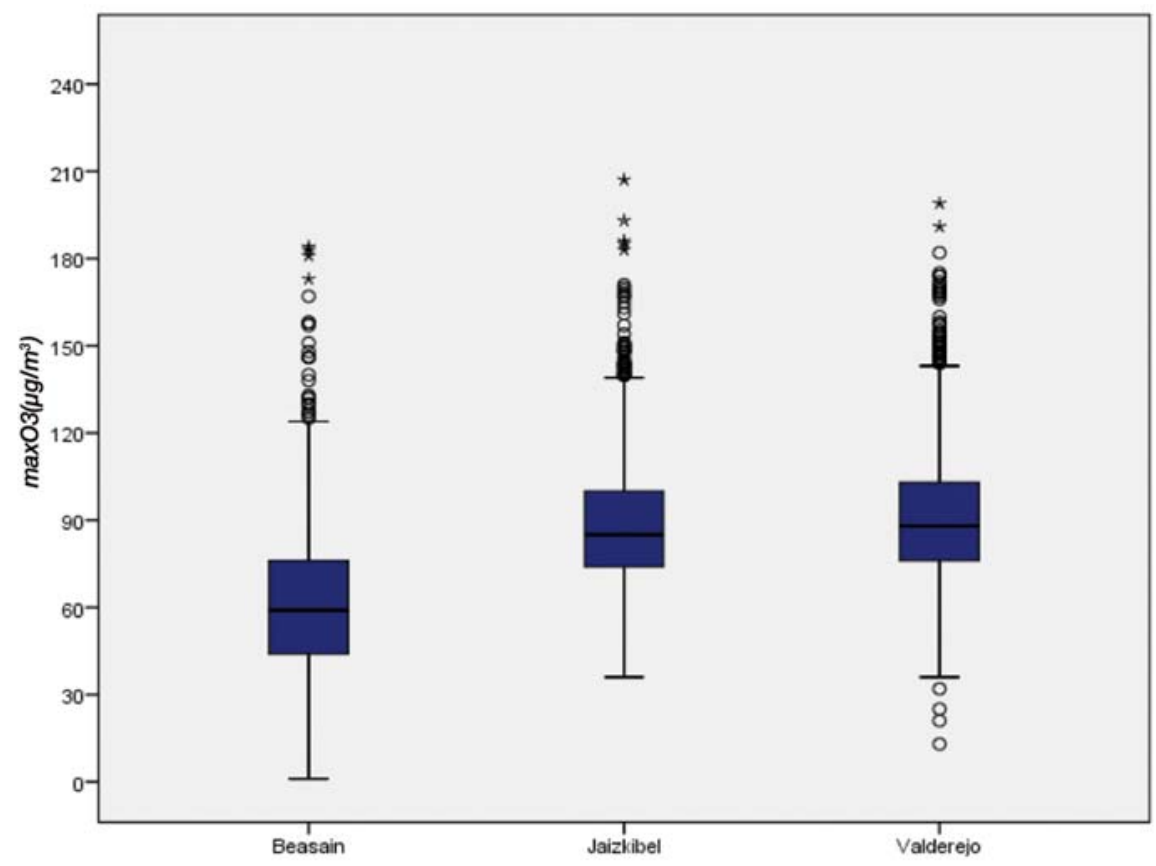

8. irudia. Eguneko ozono maila maximoak Beasain, Jaizkibel eta Valderejon (2004-2008).

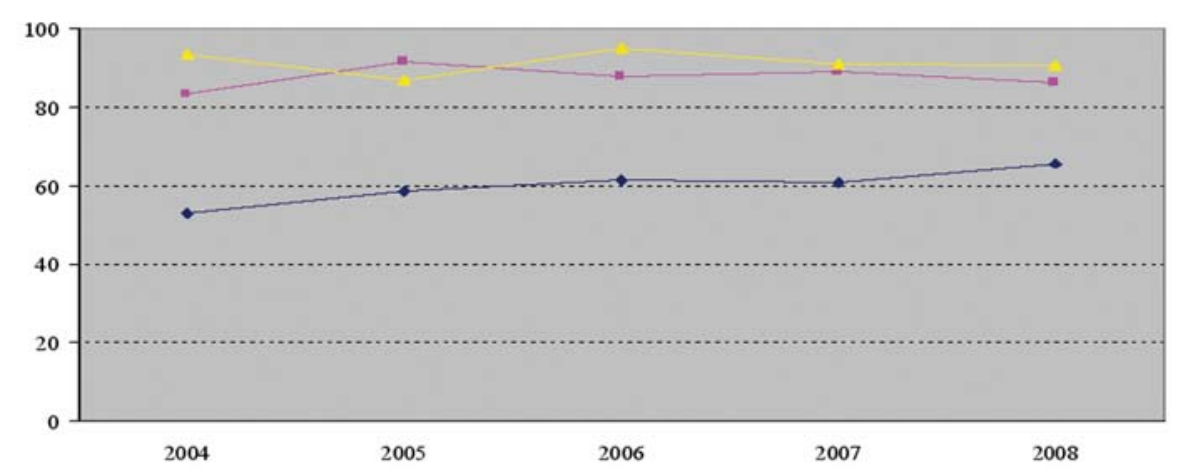

9. irudia. Eguneko ozono maila maximoen batez besteko joera Beasain (urdina), Jaizkibel (arrosa) eta Valderejon (horia) 2004-2008 denboraldian.

konplexutasunagatik, ozono kontzentrazio handienak ez dira igorpen-fokotik gertu jasotzen [12]. Bestetik, haizeak ozonoa urrutira garraia dezake, eta honegatik jaso daitezke ozono maila handiak landa-estazioetan $[13,14]$. 


\section{ONDORIOAK}

Lan honetan, aztergai hartu da EAEko Aire Kalitatea Kontrolatzeko eta Zaintzeko Sareko Beasain, Jaizkibel eta Valderejo estazioetan neurtutako eguneko ozono maila maximoen bilakaera, 2004-2008 denboraldian. Hiru kasuetan ozonoak urtez urte duen izaera ziklikoa azpimarratu behar da, eta balio handiagoak apirila eta iraila bitartean arratsalde erdian (14:00-18:00) hartzen dira, hain zuzen ere eguzki-erradiazioak indartsuagoak direnean. Ozonoagatiko aire-kalitatea ez zen izan inoiz oso txarra edo arriskutsua, jasotako ozono kontzentrazio maximoak $270 \mu \mathrm{g} / \mathrm{m}^{3}$ azpitik egon baitziren une oro. Beraz, eguneko ozono kantitate maximoek ez zuten alerta-atalasea gainditu 20042008 denboraldian aztergai diren hiru estazioetan. Hala ere, oso gutxitan izan zen ozonoagatiko aire-kalitatea txarra $\left(180-270 \mu \mathrm{g} / \mathrm{m}^{3}\right)$ : 7 Beasainen, 5 Jaizkibelen eta 4 Valderejon, ekaina eta iraila bitartean, 2006 eta 2008 urteetan. Kasu hauetan, onartu daiteke eguneko ozono maila maximoek informazioatalasea gainditu zutela. Gainontzeko egun guztietan, oro har, ozonoagatiko aire-kalitatea ona, onargarria edo ertaina izan zen \% 99an baino gehiagotan.

Hiru estazioen arteko ozono kontzentrazio maximoak konparatzen badira, minimo, maximo, batezbesteko, mediana, kuartil eta pertzentilak handiagoak izan ziren ikerketa honetako landa-estazioetan (Jaizkibel eta Valderejo). Fenomeno hau, uler daiteke ozonoaren formakuntzaren konplexutasuna eta ozonoaren garraiagarritasuna kontuan hartuta.

EAEko Aire Kalitatea Kontrolatzeko eta Zaintzeko Sarean egunero jaso eta argitaratzen dira neurtutako ozono kontzentrazioak. Biztanleriak jakin nahi du zein den arnasten duen aire-kalitatea. Era berean, biztanleen interesekoa da aldez aurretik ezagutzea giza osasunaren babeserako ozono-atalaseen gainditzeak noiz eta non gerta daitezkeen. Hori guztia kontuan hartuta, lan honen sinatzaileek airEsan izeneko software estatistikoa [15] diseinatu zuten, ozono kontzentrazio maximoen aurresanak garaiz lortzeko.

\section{ESKER ONEZ}

Eskerrak eman nahi dizkiogu Eusko Jaurlaritzako Ingurugiro Sailari, Aire Kalitatea Kontrolatzeko eta Zaintzeko Sareko datuak uzteagatik eta eskainitako finantziazioagatik.

\section{BIBLIOGRAFIA}

[1] WILLIAMSON S. J. 1973. Fundamentals of Air Pollution. Reading, Massachusetts. Addison-Wesley.

[2] WORLD HEALTH ORGANIZATION. 2000. Guidelines for Air Quality. World Health Organization, Geneva. 
[3] KONING H. W., KRETZSCHMAR J. G. 1986. «Air pollution in different cities around the world». Atmospheric Environment 20, 101-113.

[4] EUROPEAN COMMISSION. 1996. Council Directive 96/62/EC of 27 September 1996 on ambient air quality assessment and management (OJ L 296, 21.11.1996, 55 - 63).

[5] EUROPEAN ENVIRONMENT AGENCY. 2013. Air pollution by ozone across Europe during summer 2012. Overview of exceedances of EC ozone threshold values for April-September 2012. Technical report No 3 / 2013. European Environment Agency. Copenhagen.

[6] COMUNIDAD EUROPEA. 2008. Directiva 2008/50/CE relativa a la calidad del aire ambiente y a una atmósfera más limpia en Europa. Diario oficial de la Comunidad Europea. Copenague.

[7] EUSKO JAURLARITZA. 2009. http://www.ingurumena.ejgv.euskadi.net/ r49-3614/eu/contenidos/ informacion/red_calida_aire_capv/eu_975/indice_ calidad_e.html

[8] EUSKO JAURLARITZA. 2011. http://www.osakidetza.euskadi.net/r85ckserv01/eu/contenidos/informacion/contaminacion/eu_10272/fotoquimicos. html

[9] SILLMAN S. 1999. «The relation between ozone, NOx and hydrocarbons in urban and polluted rural environments». Atmospheric Environment 33, 1821-1845.

[10] VOLZ A., KLEY D. 1988. «Evaluation of the Montsouris series of ozone measurements made in the nineteenth century». Nature 332, $240-242$.

[11] STAEHELIN J., THUDIUM J., BUEHLER R., VOLZ-THOMAS A., GRABER, W. 1994. «Trends in surface ozone concentrations at Arosa (Switzerland)». Atmospheric Environment 28, 75 - 87.

[12] KLEINMAN L.I., DAUM P.H., IMRE D., LEE Y.-N., NUNNERMACKER L.J., SPRINGSTON S.R. 2002. «Ozone production rate and hydrocarbon reactivity in 5 urban areas: A cause of high ozone concentration in Houston». Geophysical Research Letters, vol. 29, no. 10, 10051-10054.

[13] GANGOITI G., ALBIZURI A. ALONSO, L., 2006. «Sub-continental transport mechanisms and pathways during two ozone episodes in northern Spain». Atmospheric Chemistry and Physics 6, 1469-1484.

[14] HOV O., SCHMIDBAUER N. 1992. «Atmospheric concentrations of nomethane hydrocarbons at a North European coastal sie». Journal of Atmospheric Chemistry 14, 515 - 526.

[15] AGIRRE E., ANTA A., BARRON L.J.R. 2010. «AirEsan: ozono mailak aurresateko sistema informatikoa». Ekaia 23, 63-73. 